\title{
The Development of a Fluorine Removal Agent Using
}

\section{Incinerated Ash}

\author{
Masaaki Takahashi ${ }^{1}$, Shrestha Rashim Bahadur ${ }^{1}$, Yukimasa Takemoto ${ }^{1}$, Maki Ooyagi ${ }^{1}$, Kati Nabin ${ }^{1}$, Adhikari \\ Jayaram $^{1}$, Eiji Yuki ${ }^{2}$ and Takanori Terazawa ${ }^{3}$ \\ 1. Yokkaichi University, Research Laboratory on Environmental Technology, Kayo-cho 1200, Yokkaichi, Mie 512-8512, Japan \\ 2. Mie Chuo Kaihatsu Co., Ltd, Hachiya 4713, Yono, Iga, Mie 518-1152, Japan \\ 3. Mie Prefectural Environmental Conservation Agency, Ueno 3258, Kawage, Tsu, Mie 510-0304, Japan
}

\begin{abstract}
Calcium-based compounds are used as fluorine removal treatment materials in water. However, due to the water solubility of calcium fluoride, there is a problem with low fluorine removal performance. For this reason, various removing agents including phosphorus have been developed. We have found that a combination of aluminum phosphate recovered from incinerated ash of the sewage sludge and refuse incineration ash has a high fluorine removal performance. At the highest removal performance, $\mathrm{F}$ ion concentration of the treated water reached $0.1 \mathrm{mg} / \mathrm{L}$, so an optimal formulation method was investigated.
\end{abstract}

Key words: Incinerated ash, fluorine removal, aluminum phosphate, water treatment.

\section{Introduction}

Fluorine is widely distributed in sea water, groundwater, etc. In recent years, many pollutants have been reported since it is widely used as an important material in semi-conductor manufacturing plants [1, 2]. High concentrations of fluorine are designated as harmful substances because they adversely affect living things, and $0.8 \mathrm{mg} / \mathrm{L}$ is adopted as an environmental standard in river water in Japan [3].

A calcium type removal agent is mainly used for removing fluorine from waste water, but with the removal agent, fluorine is removed by solid-liquid separation as calcium fluoride, but calcium fluoride is slightly dissolved in water. Therefore, for low concentration $(8 \mathrm{mg} / \mathrm{L}$ or less) of the fluorine removal, some problems have been pointed out [4]. For this reason, fluorine contamination has been reported around the IC factory [5].

Recently, some studies have been made on methods

Corresponding author: Masaaki Takahashi, researcher, research field: environmental technology. for enhancing the removal effect by using phosphate-based substances [6-8]. The authors found that elution of fluorine can be suppressed by adding aluminum phosphate-containing material (estimated as a mixture of aluminum phosphate and gypsum) recovered from the incineration ash of sewage sludge. The reports on its effect have been published [9].

\section{Methods}

\subsection{Materials}

Refuse incineration ash (referred to as raw ash) and the roasted ash (referred to as roasted ash) were used as the raw materials. The roasted ash was made by roasting the refuse incineration ash at about $1,000{ }^{\circ} \mathrm{C}$ for improving the performance of the ash. The aluminum phosphate-containing material (referred to as $\mathrm{AlPO}_{4}$ ) was extracted by adding sulfuric acid to the incineration ash of the sewage sludge, and was neutralized and recovered with addition of calcium carbonate powder. The compositions of the raw materials are shown in Table 1. The raw ashes are mainly composed of calcium and silicon, and contain a significant amount of aluminum and iron. $\mathrm{AlPO}_{4}$ is 
mainly composed of $\mathrm{Al}_{2} \mathrm{O}_{3}, \mathrm{P}_{2} \mathrm{O}_{5}, \mathrm{CaO}$, and $\mathrm{SO}_{3}$ and is considered to be a mixture of aluminum phosphate $\left(\mathrm{AlPO}_{4}\right)$ and gypsum $\left(\mathrm{CaSO}_{4}\right)[10]$.

\subsection{Test Water}

The following test waters were prepared:

Test Water I: Sodium fluoride reagent diluted with pure water to adjust the fluorine concentration to 5-30 $\mathrm{mg} / \mathrm{L}$.

Test Water II: Factory waste water containing high concentration of fluorine.

\subsection{Experiment Procedure}

In order to dissolve the phosphorus, a small amount of dilute sulfuric acid was added to $\mathrm{AlPO}_{4}$, and the mixture was kneaded in a paste state, and further raw ash was added to obtain a removal agent. This was put into Test Water I, after stirring for several minutes, filtration was carried out using a filter paper (Toyo Roshi Kaisha, ADVANTEC, 5 A), and the fluorine concentrations of the filtrate (treated water) were compared (Fig. 1).

\subsection{Analysis Method}

The analysis method is as follows:

Fluorine ion: Automatic Analyzer (Auto Analyzer, manufactured by Bertech Corp.)

Chloride ion: Silver Nitrate Titration Method

$\mathrm{PO}_{4}-\mathrm{P}$ : Ammonium Molybdate Method

$\mathrm{NO}_{3}-\mathrm{N}$ : UV Absorption Method

COD: Acid Manganese Method

Aluminum ion and $\mathrm{NO}_{2}-\mathrm{N}$ : Simple method (Pack Test, manufactured by Kyoritsu)

Calcium ion: Chelate Titration Method

Cadmium, lead, arsenic, selenium: ICP-MS

\section{Results}

\subsection{Selection of Raw Materials}

As described above, it is considered that the phosphoric acid component in $\mathrm{AlPO}_{4}$ plays an important role, but it is assumed that $\mathrm{AlPO}_{4}$ is water insoluble at neutral to weakly alkaline conditions, and it is difficult to expect the effect. Therefore, diluted sulfuric acid was added to investigate the effect of enhancing the water solubility of $\mathrm{AlPO}_{4}$. Some combination of raw materials was examined using the Test Water I, as roasted ash, $\mathrm{AlPO}_{4}$, dilute sulfuric acid were added to the test water, and filtered to examine the fluorine removal performance. As a result, the mixture of the roasted ash with $\mathrm{AlPO}_{4}$ and dilute sulfuric acid showed high removal rates (Fig. 2).

Table 1 Composition of raw ash (using X-ray analyzer).

\begin{tabular}{lllllllll}
\hline Classification & $\mathrm{SiO}_{2}$ & $\mathrm{Al}_{2} \mathrm{O}_{3}$ & $\mathrm{CaO}$ & $\mathrm{P}_{2} \mathrm{O}_{5}$ & $\mathrm{Fe}_{2} \mathrm{O}_{3}$ & $\mathrm{SO}_{3}$ & $\mathrm{Cl}$ & Other \\
\hline Raw ash & 26.4 & 7.3 & 34.9 & 1.0 & 9.7 & 4.4 & 4.6 & 11.7 \\
Roasted ash & 17.8 & 5.3 & 41.6 & 1.6 & 9.3 & 3.2 & 10.6 & 10.6 \\
$\mathrm{AlPO}_{4}$ & 0.1 & 12.7 & 31.0 & 21.8 & 2.6 & 31.4 & $<0.1$ & 0.4 \\
\hline
\end{tabular}

Unit: \%.

Raw ash or roasted ash,

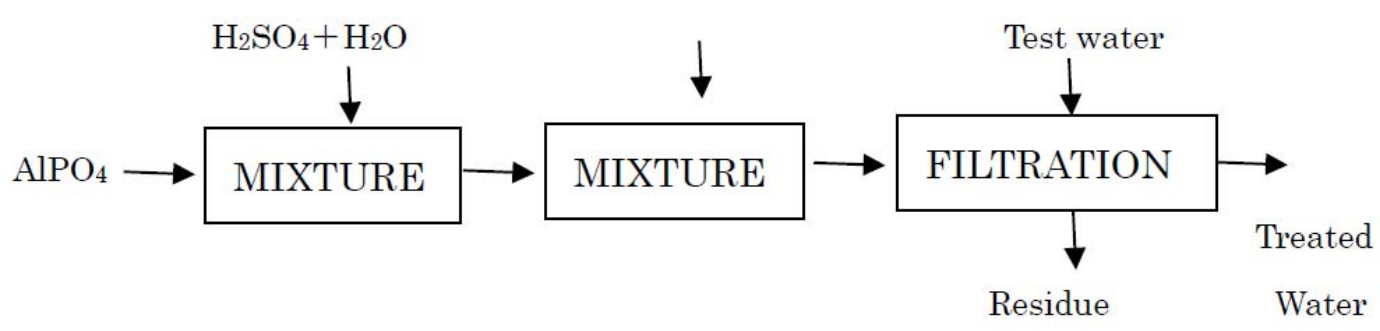

Fig. 1 Experiment procedure. 


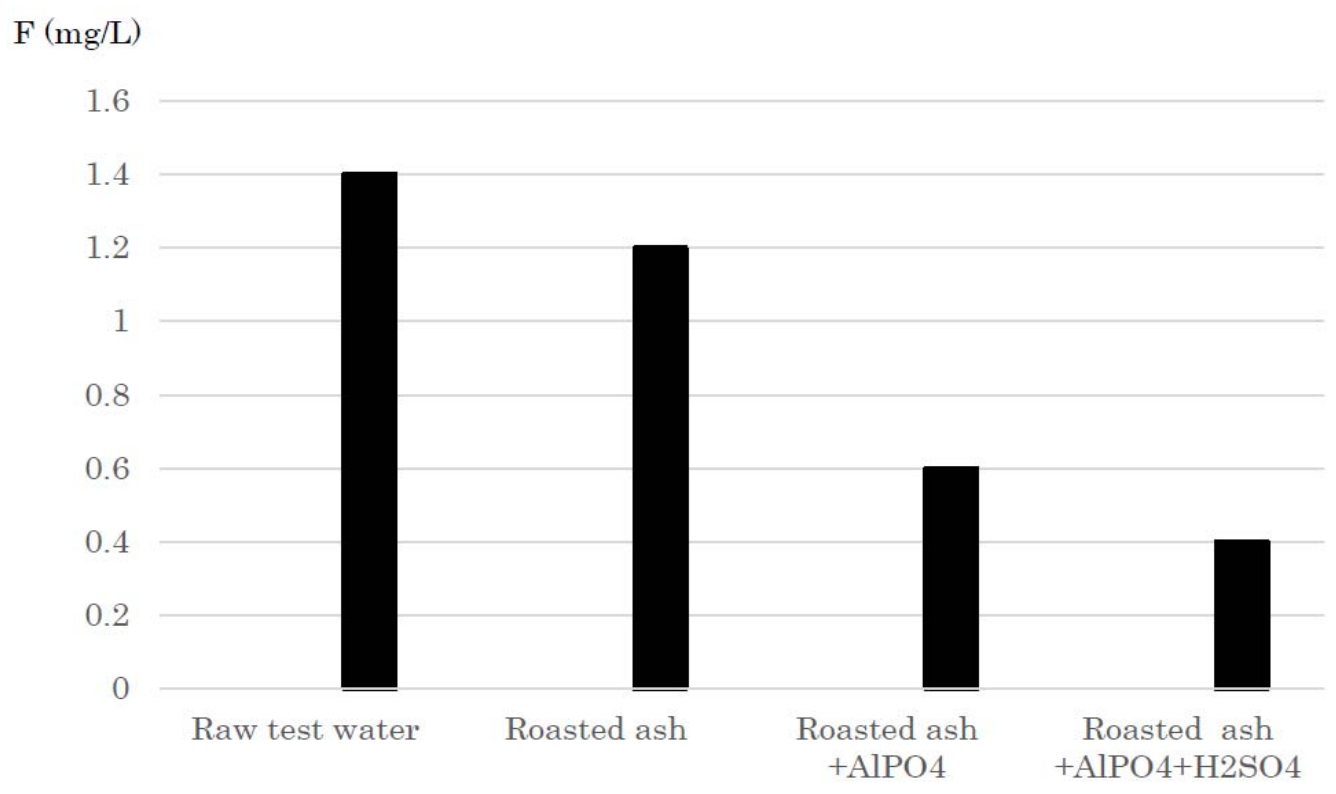

Fig. 2 Combination of raw materials and fluorine removal performance.

\subsection{Investigation of Fluorine Removal Condition}

As mentioned, roasted ash, $\mathrm{AlPO}_{4}$ with dilute sulfuric acid showed high fluorine removal effect, in order to clarify the appropriate blending ratio of refuse incineration ash, $\mathrm{AlPO}_{4}$ and diluted sulfuric acid, diluted sulfuric acid (1+9) were added to $1 \mathrm{~g}$ of $\mathrm{AlPO}_{4}$ in various formulations. To achieve sufficient blending, $3 \mathrm{~mL}$ of water was further added to the mixture, and after stirring, $5 \mathrm{~g}$ of the raw ash or roasted ash was added to them, and the basic experiment was carried out. In the case of raw ash, the addition rate of diluted sulfuric acid was $0 \mathrm{~mL}$ to 1 $\mathrm{mL}$ (Fig. 3), and in the case of roasted ash, $0.5 \mathrm{~mL}$ to $1 \mathrm{~mL}$ (Fig. 4) showed particularly high fluorine removal effect, and the fluorine concentration in the treated water became $0.1 \mathrm{mg} / \mathrm{L}$ or less. On the contrary, when the addition amount of sulfuric acid was further increased, the fluorine removing effect was lost, showing a fluorine concentration higher than that of raw water, and the elution of the fluorine contained in incinerated ash was considered. As a result of examining an appropriate blend of raw ash and $\mathrm{AlPO}_{4}$, it was judged that $5 \mathrm{~g}$ or more of raw ash was required for $1 \mathrm{~g}$ of $\mathrm{AlPO}_{4}$. When the fluorine concentration of the raw water was increased, it showed that a good removal rate was maintained when the fluorine concentration of raw water was in the range of $3 \mathrm{mg} / \mathrm{L}$ to $20 \mathrm{mg} / \mathrm{L}$ (Fig. 5). When the solid-liquid ratio of the test water and the treatment agent was changed, the removal effect could be confirmed from $100 \mathrm{~mL}$ till $1,000 \mathrm{~mL}$ of raw water with $5 \mathrm{~g}$ of raw ash (Fig. 6).

\subsection{Wastewater Treatment Experiment}

Based on the test results described above, a mixture of raw materials at ratios considered to be optimum (raw ash $5 \mathrm{~g}+\mathrm{AlPO}_{4} 1 \mathrm{~g}+(1+9)$ sulfuric acid $1 \mathrm{~mL}+$ water $3 \mathrm{~mL}$ ) was used as a fluorine treatment agent and a water treatment experiment was conducted. In the experiment, the aforementioned treatment agent was added to $500 \mathrm{~mL}$ of test water, stirred for several minutes, filtered using a filter paper, and the filtrate was analyzed. The analysis results of the test water are shown in Table 2.

Fluorine in the treated water decreases from $8 \mathrm{mg} / \mathrm{L}$ to $0.7 \mathrm{mg} / \mathrm{L}$ for Test Water I, from $1.8 \mathrm{mg} / \mathrm{L}$ to 0.4 $\mathrm{mg} / \mathrm{L}$ for Test Water II, respectively and it was possible to keep it below the environmental standard. 


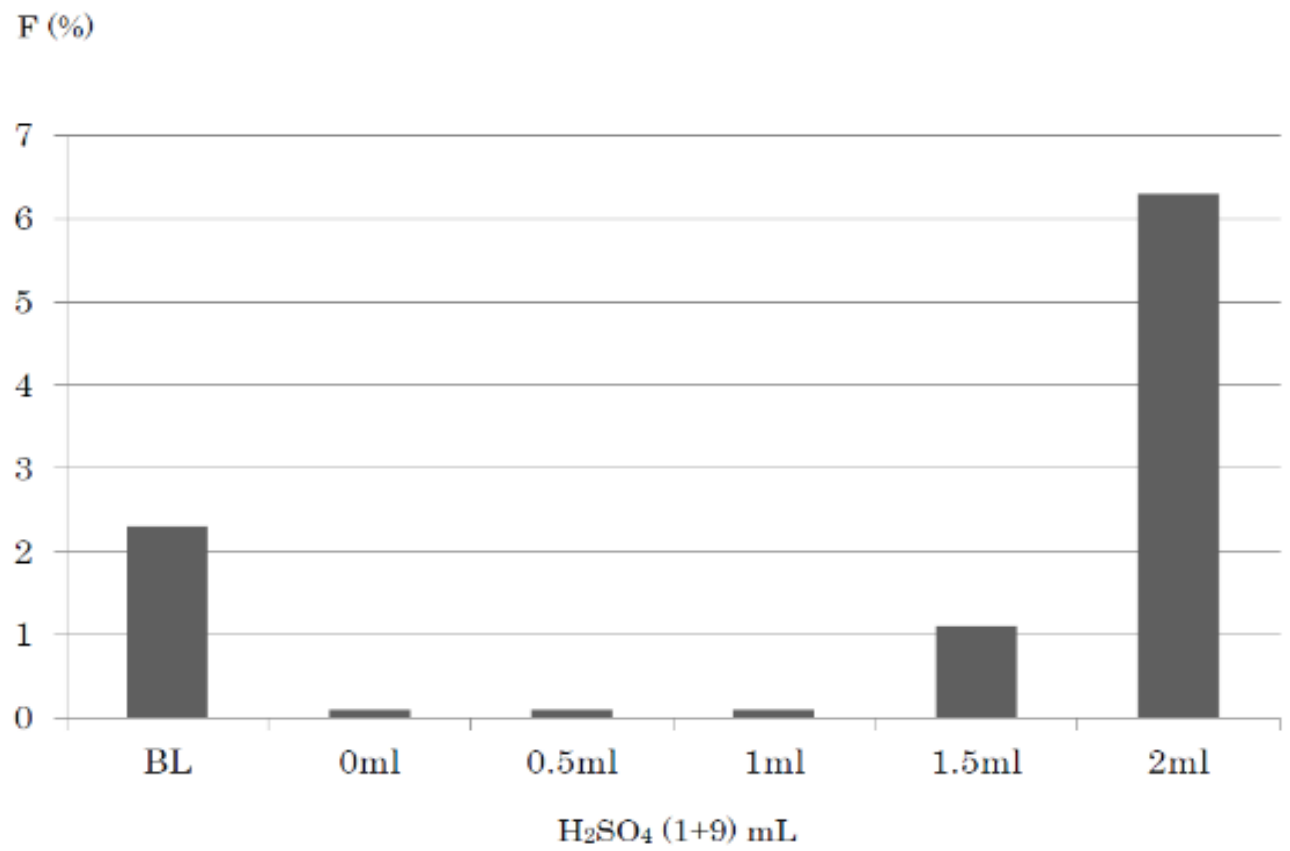

Fig. 3 Amount of sulfuric acid added and $F$ conc. of the treatment liquid (in the case of raw ash).

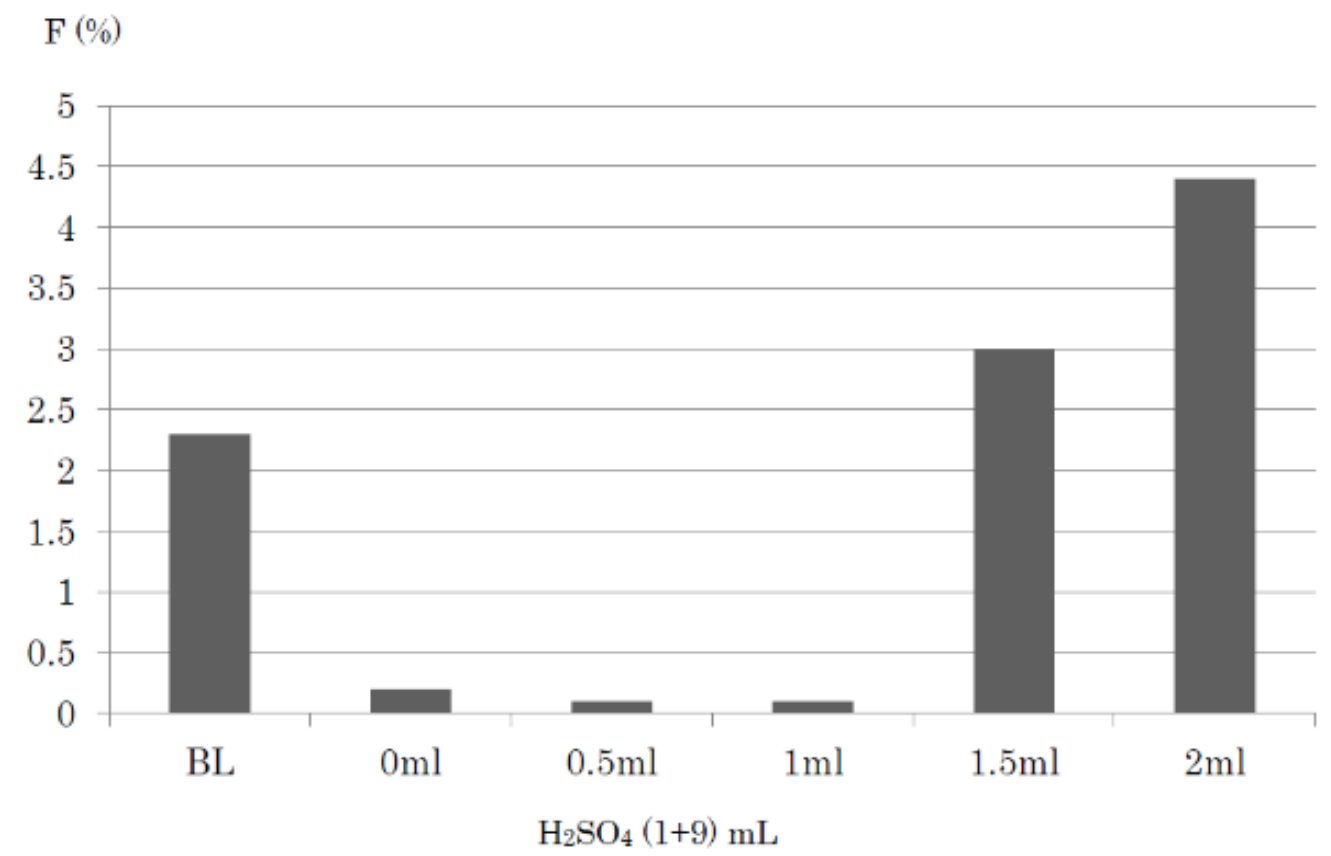

Fig. 4 Amount of sulfuric acid added and F conc. (in the case of roasted ash). 
F Removal rate (\%)

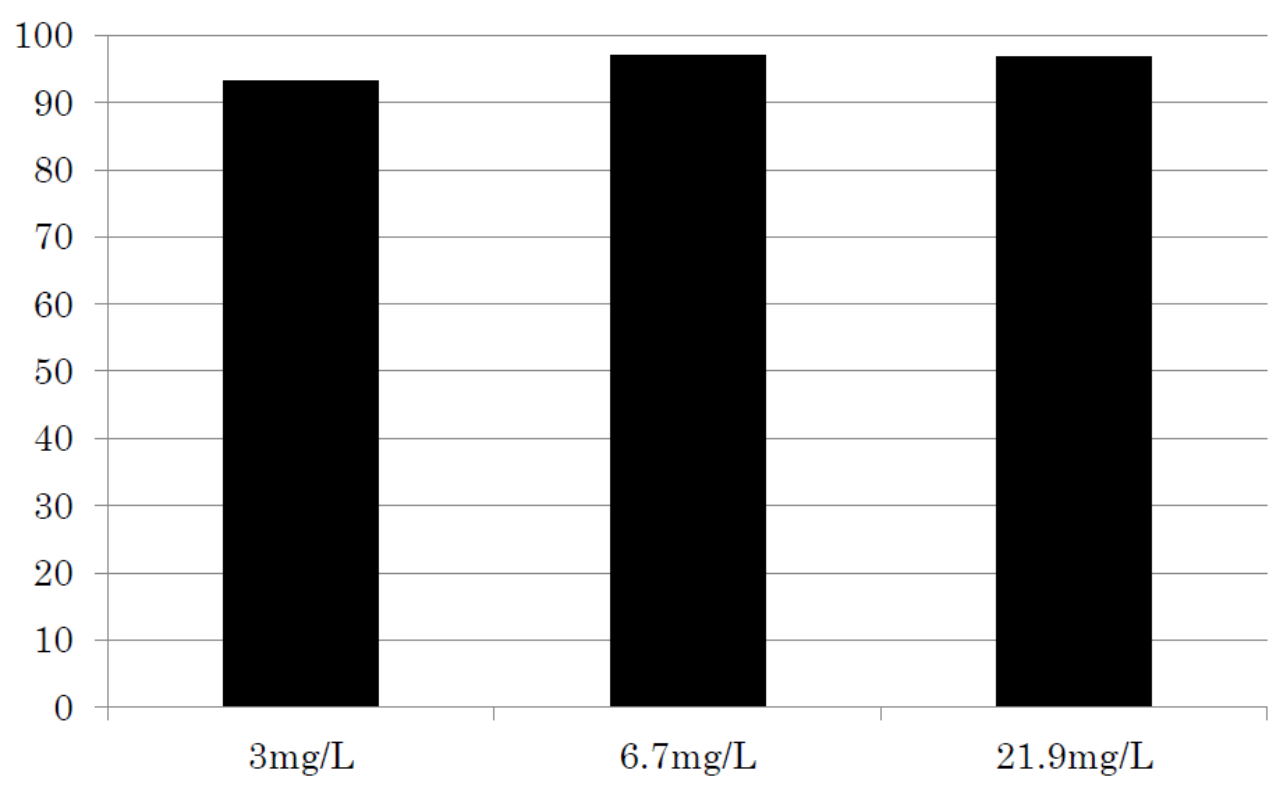

$\mathrm{F}$ conc. of the raw water

Fig. 5 Relation with $F$ conc. of the raw water and removal rate.

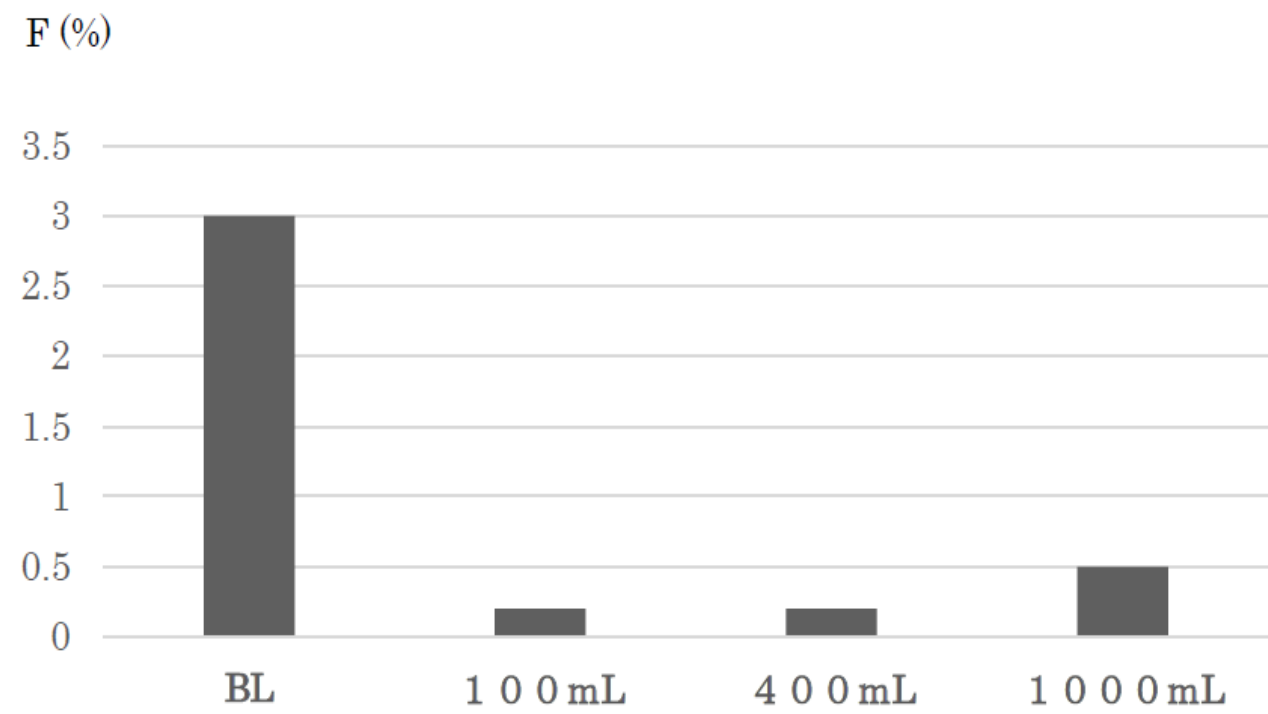

Treated water (volume $\mathrm{mL}$ )

Fig. 6 Relation of the $F$ ion concentration and the volume of treated water. 
Table 2 Fluorine removal test result (using raw ash).

\begin{tabular}{lllllllllll}
\hline & $\mathrm{pH}$ & $\mathrm{EC}$ & $\mathrm{F}$ & $\mathrm{COD}$ & $\mathrm{NO}_{3}-\mathrm{N}$ & $\mathrm{NO}_{2}-\mathrm{N}$ & $\mathrm{PO}_{4}-\mathrm{P}$ & $\mathrm{CL}$ & $\mathrm{Ca}$ & $\mathrm{Al}$ \\
\hline Test Water I & 8.2 & 0.048 & 8.0 & $<0.5$ & 0.13 & $\mathrm{ND}$ & 0.03 & 11 & $<10$ & $\mathrm{ND}$ \\
Treated Water & 6.9 & 1.2 & 0.7 & 7.4 & 1.3 & $\mathrm{ND}$ & 0.34 & 210 & 410 & $\mathrm{ND}$ \\
Test Water II & 7.1 & 2.1 & 1.6 & 3.8 & 2.0 & 0.05 & 0.01 & 1,200 & 260 & $\mathrm{ND}$ \\
Treated Water & 6.7 & 2.7 & 0.4 & 11 & 3.0 & 0.05 & 0.36 & 1,400 & 610 & $\mathrm{ND}$ \\
\hline
\end{tabular}

Unit: EC: $\mathrm{mS} / \mathrm{cm}$, Others: $\mathrm{mg} / \mathrm{L}$.

Table 3 Hazardous substance test results.

\begin{tabular}{lllll}
\hline & $\mathrm{Cd}$ & $\mathrm{Pb}$ & $\mathrm{As}$ & $\mathrm{Se}$ \\
\hline Test Water I & $<0.005$ & $<0.005$ & $<0.005$ & $<0.002$ \\
Treated Water & $<0.005$ & $<0.005$ & $<0.005$ & $<0.002$ \\
Test Water II & $<0.005$ & $<0.005$ & $<0.005$ & $<0.002$ \\
Treated Water & $<0.005$ & $<0.005$ & $<0.005$ & $<0.002$ \\
\hline
\end{tabular}

Similarly in the case of roasted ash, it decreased from $5.4 \mathrm{mg} / \mathrm{L}$ to $0.5 \mathrm{mg} / \mathrm{L}$ (Test Water I), from $1.9 \mathrm{mg} / \mathrm{L}$ to $0.3 \mathrm{mg} \mathrm{L}$ (Test Water II).

The $\mathrm{pH}$ of the treatment water slightly decreased, the $\mathrm{EC}$ was about $1 \mathrm{mS} / \mathrm{cm}$, and the calcium ion increased by about $400 \mathrm{mg} / \mathrm{L} . \quad \mathrm{PO}_{4}-\mathrm{P}$ increased slightly (about $0.3 \mathrm{mg} / \mathrm{L}$ ). The decrease in $\mathrm{pH}$ may be due to the sulfuric acid added to make the treating agent. EC, calcium and $\mathrm{PO}_{4}-\mathrm{P}$ are considered to be eluates from the treating agent. Chloride ion increased by about $200 \mathrm{mg} / \mathrm{L}, \mathrm{NO}_{3}-\mathrm{N}$ by $1 \mathrm{mg} / \mathrm{L}$, and COD by about $7 \mathrm{mg} / \mathrm{L}$, respectively. Raw ash is incineration ash of municipal waste, and weight loss on heating is about $10 \%$. It is highly probable that it contains various half burned substances, organic contaminants and chloride, which is presumed to be this influence. No significant change was observed for $\mathrm{NO}_{2}-\mathrm{N}$ and $\mathrm{Al}$ ions. In the test results of harmful substances such as cadmium, lead, arsenic, selenium, etc., contaminants were not found in the treated water, and it was judged that there was no elution of harmful substances from incinerated ash as raw material (Table 3).

\section{Consideration}

Regarding the removal effect of fluorine, two scenarios are considered: the apatite formation with calcium phosphate [11] which has very low solubility of fluorine, and the formation of the Ettringite compound [12] which absorb fluorine ions.
The fluorine treatment agent prepared by adding raw ash, $\mathrm{AlPO}_{4}, \mathrm{H}_{2} \mathrm{SO}_{4} \quad(1+9)$ was dried and investigated by $\mathrm{X}$-ray diffraction (manufactured by Rigaku Co. Ltd.). In Ettringite, a notable peak appears at the incident angle (20) around 8 degrees (cited from Dr. Kamimoto's research, in Fig. 7), but the peak assumed to be such Ettringite was not found in this removal agent (Fig. 8). This suggests that insolubilization due to apatite formation progressed.

It is considered possible to produce a fluorine removal agent using aluminum phosphate recovered from the incineration ash of sewage sludge and various incineration ashes. In developing for the future, in the case of fluorine removal agents, it is necessary to eliminate elution of unnecessary salts from the removal agent. $\mathrm{Cl}^{-}$or $\mathrm{NO}_{3}-\mathrm{N}, \mathrm{COD}$ etc. and, it is thought to be improved by using biomass incineration ash, fly ash or inorganic natural materials with less unburnt substances and incompatible materials instead of municipal waste incineration ash. Components such as calcium and phosphorus are indispensable components for the treatment agent itself, but it is necessary to consider elution reduction methods by adding raw materials or adding carbonate compounds during the treatment process. Although no remarkable elution of harmful substances was observed in the present study, harmful substances in the incineration ash vary depending on their emission sources, so it is necessary to check each type of raw ash to be used. 


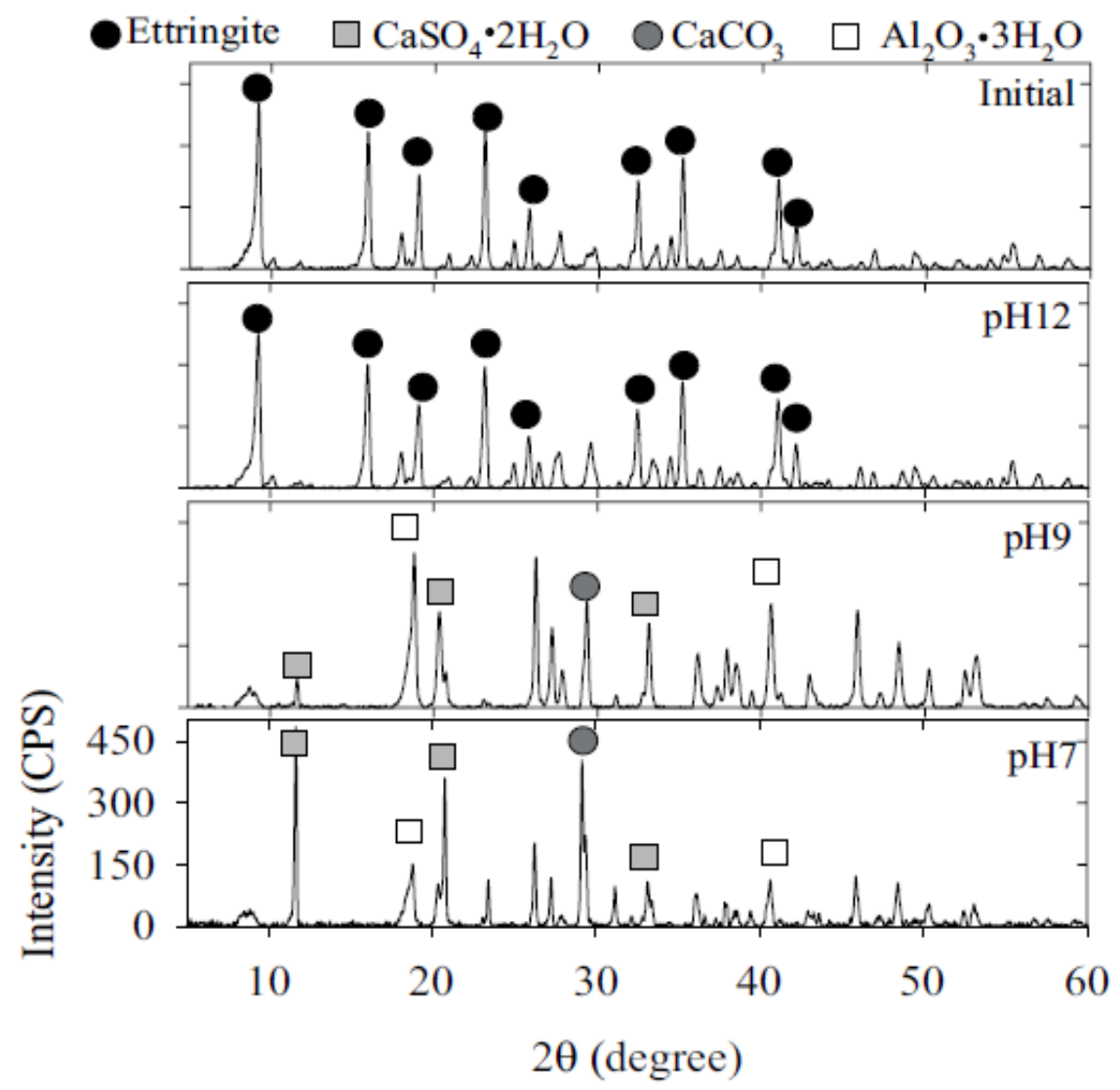

Fig. 7 X-ray diffraction spectrum of Etringuide (study of Kamimoto [12]).

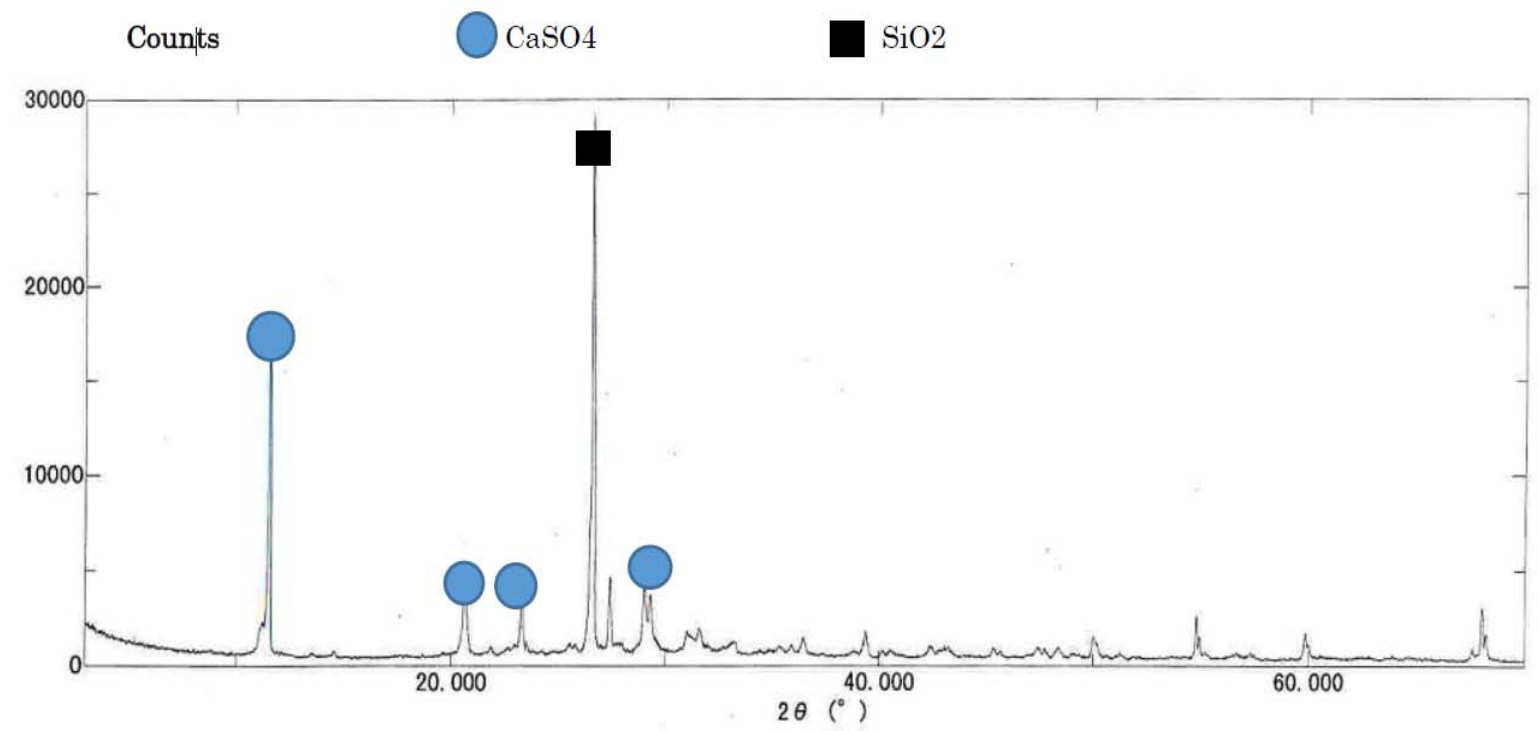

Fig. 8 X-ray diffraction spectrum of the treating agent. 


\section{Summary}

Using $\mathrm{AlPO}_{4}$ recovered from garbage incineration ash and sewage sludge incineration ash as raw material, it was possible to remove fluorine at a low concentration. It is considered that an inexpensive removal agent can be produced by using these raw materials. However, when using this agent, it is considered that there is an influence of calcium and other salts from the raw ash as well as impurities in the ash in the treated water. So, it is also necessary to pursue investigations on incineration ash containing a small amount of impurities or fluorine removing agents using various substitute materials including calcium and aluminum.

\section{Acknowledgements}

The authors wish to express their appreciation to Dr. Hayashi (Mie Prefectural Institute of Industrial Technology) for his assistance with the X-ray analysis, and also to Dr. Eric Bray (Professor of Yokkaichi University) for his advice on making the article. The authors also express their appreciation to the Hinaga Wastewater Treatment Center (Yokkaichi City Government, Waterworks and Sewage Bureau) offering us the ash.

\section{References}

[1] The Society of Fluorine Chemistry, Japan, Fluorine Atom Related Products Enrich Our Daily Lives. Accessed Jan. 20th 2019. http://sfcj.jp/en/index.html.

[2] Shizen yurai niyorudozyouosenn no hanntei (Judgment Method of the Soil Pollution Derived by Natural Pollution). Accessed Jan. 20th 2019. http://www.pref.osaka.lg.jp/attach/4908/00021879/23120 1_s1_1.pdf\#search=\%27\%E3\%83\%95\%E3\%83\%83\%E7 $\% \mathrm{~B} 4 \% \mathrm{~A} 0 \% \mathrm{E} 6 \% \mathrm{~B} 1 \% 9 \mathrm{~A} \% \mathrm{E} 6 \% 9 \mathrm{~F} \% 93 \% 27$.

[3] Environmental Quality Standards for Water Pollution. Ministry of the Environment Government of Japan.
Accessed Jan. 20th 2019.

https://www.env.go.jp/en/water/wq/wp.pdf.

[4] Kosaku, O., Sei, Y., and Yosiaki, S. "Advanced Water Treatment for Fluorides-Containing Waste Water." U.D.C. 628. 543. 4:546. 161. Accessed Jan. 20th 2019. http://www.hitachihyoron.com/jp/pdf/1976/03/1976 03 10.pdf\#search $=\% 27 \% \mathrm{E} 3 \% 83 \% 95 \% \mathrm{E} 3 \% 83 \% 83 \% \mathrm{E} 7 \% \mathrm{~B} 4$ $\%$ A0\%Е9\%99\%A4\%Е5\%8E\%BB\%Е3\%82\%AB\%Е3\%8 3\%AB\%E3\%82\%B7\%E3\%82\%A6\%E3\%83\%A0\%27.

[5] Yukimasa, T., Masaaki, T., Maki, O., Masashi, S., Zirou, I., Naoki, S., and Takanori, T. 2017. "Water Pollution of Kaizou-Gawa River." The Journal of Yokkaichi University 30 (1): 171-81.

[6] Mitsubishi Materials Corporation. 2011. Accessed Jan. 20th 2019 , https://www.mmc.co.jp/corporate/ja/news/press/2011/111221.pdf\#search= $\% 27 \% \mathrm{E} 3 \% 83 \% 95 \% \mathrm{E} 3 \% 83 \% 83 \% \mathrm{E} 7 \%$ B4\%A0\%Е9\%99\%A4\%Е5\%8Е\%BB\%Е6\%96\%B9\%Е6 $\% \mathrm{~B} 3 \% 95 \% 27$.

[7] NEDO: News Release, Koukinou Husso Syorizai wo Kaihastu (in Japanese). Accessed Jan 20th 2019 http://www.nedo.go.jp/news/press/AA5_100042.html.

[8] Takahiko, Kajima. "Restoration of Soil Polluted with Fluorine Using the Material Containing Phosphorus from Incineration Ash of Chicken Manure." Unpublished report of the University of Miyazaki, Civil and Environmental Engineering.

[9] Masaaki, T., Yukimasa, T., Maki, O., Shrestha, R. B., Kati, N., Adhikari, J., Eiji, Y., Kouichi, S., and Takanorii, T. 2018. "Development of Fluorine Removal Agent Using Incinerated Ash." In Proceedings of the 7th Annual Conference of the Japan Society of Waste Management Expert.

[10] Masaaki, T., Susumu, K., Hiroshi, S., Eiji, S., Takao, I., Syuji, H., and Hideo, M. 2003. "Technology for Recovering Phosphorus from Incinerated Wastewater Treatment Sludge." Chemosphere 44: 23-9.

[11] Masahiko, K., Hideki, M., Tetsuya, H., and Takeshi, S. 2013. "Lead Sorption from Aqueous Solution Using Apatite and Residue Ash Recovered from Sewage Sludge Ash.” J STAGE 69 (7): 281-90.

[12] Yuki, K., Keita, O., Ryoichi, I., Kyung-Sok, M., Koo-Ho, K., and Yong-Jun, J. 2017. "Removal Properties of Phosphate Witty Ettringite." Desalination and Water Treatment 63: 476-82. 